\title{
Glass-Forming Ability of Fe-Ni Alloys Substituted by Group V and VI Transition Metals (V, Nb, Cr, Mo) Studied by Thermodynamic Modeling
}

\begin{abstract}
Z. ŚNIADECKI
The glass-forming ability (GFA) of Fe-Ni-TM alloys, where $\mathrm{TM}=\mathrm{V}, \mathrm{Nb}, \mathrm{Cr}, \mathrm{Mo}$, was determined utilizing thermodynamic modeling. Enthalpies of formation of amorphous state were calculated and analyzed along with normalized mismatch entropy and glass-forming ability parameter. All thermodynamic quantities were qualitatively compared with enthalpies of formation of solid solution and experimental results. Due to the fact that FeNi-based amorphous ribbons are used nowadays in magnetoelastic sensors (MES), which can be used in biomedical or chemical applications, discussion is concentrated mainly on the substitution effect of group V and VI transition metals on the improvement of GFA. In this sense, group V elements are preferred, with $\mathrm{Nb}$ as the most promising candidate among all analyzed $\mathrm{TM}$ elements. This is a consequence of significant differences of potential and density of electrons at the boundary of Wigner-Seitz cell comparing to $\mathrm{Fe}$ and $\mathrm{Ni}$, which in turn leads to more negative values of interfacial enthalpy and higher driving force for vitrification.
\end{abstract}

https://doi.org/10.1007/s11661-020-05897-9

(C) The Author(s) 2020

\section{INTRODUCTION}

FENI-BASED amorphous ribbons are widely used as magnetoelastic sensors (MES) nowadays, and due to their outstanding properties can be utilized in biomedical or chemical applications. ${ }^{[1,2]}$ Such sensors in a form of freestanding objects/particles or cantilevers are usually built of magnetostrictive $\mathrm{Fe}_{40} \mathrm{Ni}_{38} \mathrm{Mo}_{4} \mathrm{~B}_{18}$ (Metglas $2826 \mathrm{MB}) \cdot{ }^{[3]}$ Due to limited sensitivity of relatively thick ribbons, which reaches only about $50 \mathrm{~Hz} / \mu \mathrm{g}{ }^{[4]}$ there is a challenging task to designing material with excellent soft magnetic properties, maximized magneto-mechanical coupling constant and with reduced dimensions. Therefore, some groups aimed to prepare such alloys in a form of thin films, with $\mathrm{FeB}$, FeNiMo, FeNiB, FeNiAl and $\mathrm{FeNiMoB}$ as the most promising examples. ${ }^{[4-6]}$ The main issues, which need to be addressed, is the presence of cracks in sputtered samples, corrosion and deterioration of soft magnetic properties, usually connected with the presence of inhomogeneities. The general aim of undertaken studies is synthesis of FeNi-based thin film with magnetic properties comparable to Metglas $2826 \mathrm{MB}$, with reduced number of elements. It is also intended to determine the influence of homogeneity of

Z. ŚNIADECKI is with the Institute of Molecular Physics, Polish Academy of Sciences, M. Smoluchowskiego 17, 60-179 Poznań, Poland. Contact e-mail: sniadecki@ifmpan.poznan.pl

Manuscript submitted April 17, 2020.

Article published online July 1, 2020 amorphous structure on soft magnetic properties, which will be beneficial in further development of such materials. It can be done by variation of conditions of sputtering process, where formation of homogenous (with different packing density) and inhomogenous amorphous films (nanoglasses) ${ }^{[7,8]}$ is expected. The addition of some transition metal elements could be also used to hinder corrosion process. This particular studies focus on the calculations of formation enthalpies of amorphous alloys in Fe-Ni-TM system, where TM = $\mathrm{V}, \mathrm{Cr}, \mathrm{Nb}, \mathrm{Mo}$. It will give an insight into glass forming ability (GFA) of these ternary alloys, which will serve as a hint in designing of amorphous films with specific structure and morphology. Takeuchi and Inoue have already shown that the mixing enthalpy for $\mathrm{Ni}$ and $\mathrm{Fe}$ with transition metals listed above is negative with the most negative values for $\mathrm{Fe}-\mathrm{V}, \mathrm{Ni}-\mathrm{V}, \mathrm{Fe}-\mathrm{Nb}$ and $\mathrm{Ni}-\mathrm{Nb}^{[9]}$ Alloying is believed to result in synthesis of thin films with assumed properties described above. The GFA is the feature which matters the most in designing process, as it determines further possibilities of vitrification and reflects the tendency for amorphous state formation. It can be determined in many different ways, including experimental and theoretical methods. ${ }^{[10-13]}$ Thermodynamic approach utilizing semi-empirical Miedema's model ${ }^{[14-17]}$ is used in the present paper to determine GFA of ternary Fe-Ni-TM alloys, where TM represent group V and VI transition metals. 


\section{CALCULATIONS}

Determination of enthalpies of formation and the GFA is based on the semi-empirical Miedema's model. $^{[14,15]}$ Various quantities are used throughout the paper as GFA indicators, namely: enthalpy of formation of amorphous phase $\Delta H^{\mathrm{am}}$, normalized mismatch entropy $S_{\sigma} / k_{\mathrm{B}},{ }^{[18]}$ which reflects the effect of atomic radius mismatch and glass forming ability parameter $\Delta P_{H S}$, which is the product of chemical enthalpy $\Delta H^{\text {chem }}$ and mismatch entropy. ${ }^{[13]}$ All quantities were determined for the compositions changed with 1 at. pct step. The calculations are described in more details in Reference 16.

Each atom is represented by a block with the Wigner-Seitz cell as its boundary in the utilized theory. The alloying is simulated by the virtual process, where $A$ element atoms are solved in a matrix of $B$ atoms with concomitant changes of enthalpy. Molar volume $V$, potential $\varphi$ (similar to the work function of electron) and density at the boundary of Wigner-Seitz cell $n_{\mathrm{ws}}$ are the main quantities which play a role in enthalpy changes upon alloying. In the end, the process of solving one mole of $A$ atoms in an excess of $B$ atoms is described by interfacial enthalpy $\Delta H^{\text {inter }}(A \operatorname{in} B)$ and is defined as follows:

$$
\Delta H^{\mathrm{inter}}(A \operatorname{in} B)=\frac{V_{A}^{2 / 3}}{\frac{1}{2}\left(\frac{1}{n_{\mathrm{wsA}}^{1 / 3}}+\frac{1}{n_{\mathrm{wsB}}^{1 / 3}}\right)}\left\{-P(\Delta \varphi)^{2}+Q\left(\Delta n_{\mathrm{ws}}^{1 / 3}\right)^{2}\right\}
$$

where $P$ and $Q$ are empirical proportionality constants dependent on alloying elements. In further step one can determine $\Delta H^{\text {chem }}$, which is the chemical contribution due to the mixing of components, and for binary alloy is equal to:

$$
\Delta H^{\text {chem }}=c_{A} c_{B}\left(c_{B}^{\mathrm{s}} \Delta H^{\text {inter }}(A \text { in } B)+c_{A}^{\mathrm{s}} \Delta H^{\mathrm{inter}}(B \text { in } A)\right),
$$

with $c_{A}$ and $c_{B}$ as fractions of $A$ and $B$ atoms, and $c_{A}^{\mathrm{s}}=\frac{c_{A} V_{A}^{2 / 3}}{c_{A} V_{A}^{2 / 3}+c_{B} V_{B}^{2 / 3}}$ and $c_{B}^{\mathrm{s}}=\frac{c_{B} V_{B}^{2 / 3}}{c_{A} V_{A}^{2 / 3}+c_{B} V_{B}^{2 / 3}}$ as surface fractions. Then, the formation enthalpy of the amorphous phase can be expressed as:

$$
\Delta H^{\mathrm{am}}=\Delta H^{\mathrm{chem}}-\Delta H^{\mathrm{topo}},
$$

where $\Delta H^{\text {topo }}$ is a topological contribution, which reflects disorder in the amorphous state. The thermodynamic properties of sub-binaries were extrapolated to determine GFA of ternary alloys with the use of geometric model. ${ }^{[19-21]}$

Formation enthalpy of solid solutions was also calculated as a reference (see "Appendix"). It contains chemical contribution, but instead of topological one, taken into account for amorphous state, depends on the elastic enthalpy $\Delta H^{\text {elast }}$ (connected with the atom size mismatch) and the structural one $\Delta H^{\text {struct }}$, which originates from the valence and the crystal structure of the solvent and the solute atoms. Structural term was not taken into account in the analysis (elucidated in more details in the Section III). Differences of enthalpies of amorphous phase and a solid solution $\Delta H^{\mathrm{am}-\mathrm{ss}}=$ $\Delta H^{\mathrm{am}}-\Delta H^{\mathrm{ss}}$ are also analyzed for direct comparison of counterparts competing during solidification process.

\section{RESULTS AND DISCUSSION}

Formation enthalpies of amorphous phase were calculated with a step of 1 at. pct for Fe-Ni-TM system, where TM are chosen $3 d$ and $4 d$ transition metal elements, namely $\mathrm{V}, \mathrm{Cr}, \mathrm{Nb}$, and Mo. Composition dependences of $\Delta H^{\mathrm{am}}$ are shown in Figure 1. Looking across the phase diagram, more negative values of enthalpy of formation, which indicate higher driving force for vitrification, were obtained for $\mathrm{V}$ and $\mathrm{Nb}$, which belong to group $\mathrm{V}$ in the periodic table (in contrast to group VI elements, chromium and molybdenum). Such behavior is mainly governed by larger differences of potential $(\varphi)$ and density of electrons at the boundary of Wigner-Seitz cell $\left(n_{\mathrm{ws}}\right)$ between $\mathrm{Fe} / \mathrm{Ni}$ and group $\mathrm{V}$ elements in comparison to group VI. Potential is equal to 4.93 and $5.2 \mathrm{~V}$ for $\mathrm{Fe}$ and $\mathrm{Ni}$, respectively, while it drops to $4.25 \mathrm{~V}$ for vanadium and $4.05 \mathrm{~V}$ for niobium. For both group VI elements $\varphi$ is equal to $4.65 \mathrm{~V}$. In turn, $n_{\mathrm{ws}}$ equals to $5.55,5.36,4.41$, 4.41, 5.18 and 5.55 for $\mathrm{Fe}, \mathrm{Ni}, \mathrm{V}, \mathrm{Nb}, \mathrm{Cr}$ and $\mathrm{Mo}$, respectively, showing similar trend. Due to that interfacial enthalpies $\Delta H^{\text {inter }}(A \operatorname{in} B)$ and $\Delta H^{\text {inter }}(B \operatorname{in} A)$ are most negative for $\mathrm{Fe}-\mathrm{Nb}, \mathrm{Ni}-\mathrm{Nb}, \mathrm{Fe}-\mathrm{V}$ and $\mathrm{Ni}-\mathrm{V}$ pairs. Mentioned variation of all described quantities influences chemical contribution to $\Delta H^{\mathrm{am}}$ and formation enthalpy of amorphous phase in total, most significantly.

It should be underlined here that the aim of undertaken research is to show trends of GFA within particular phase diagrams. One should bear in mind that the detailed analysis of mutual correlations between $\mathrm{Cr}, \mathrm{V}, \mathrm{Nb}$ and Mo containing alloys is not possible, as formation enthalpies of possible counterparts competing during synthesis process (solid solution, intermetallic phases) were not taken into account. As the situation is very complex for the systems containing three transition metals, solid solution formation enthalpies $\Delta H^{\mathrm{ss}}$ were calculated just for comparison taking into account chemical and elastic contributions (Figure A1 in Appendix). Structural term was omitted as being difficult to estimate precisely. Even for binary transition metal systems, according to Bakker, ${ }^{[15]}$ such structural term should be treated as a rough estimation only. Nevertheless, it should be stated here that structural contribution for analysed TM substitutions should be similar, according to structural enthalpies of binaries. ${ }^{[15]}$ Moreover, one should expect that solid solutions and intermetallic phases will be energetically preferred in the vast number of compositions throughout the presented phase diagrams. Therefore, specific kinetic conditions will be required (e.g., sputtering) to avoid crystallization. The aim, as stated in the introduction, is the indication of compositions with the highest probability of formation 

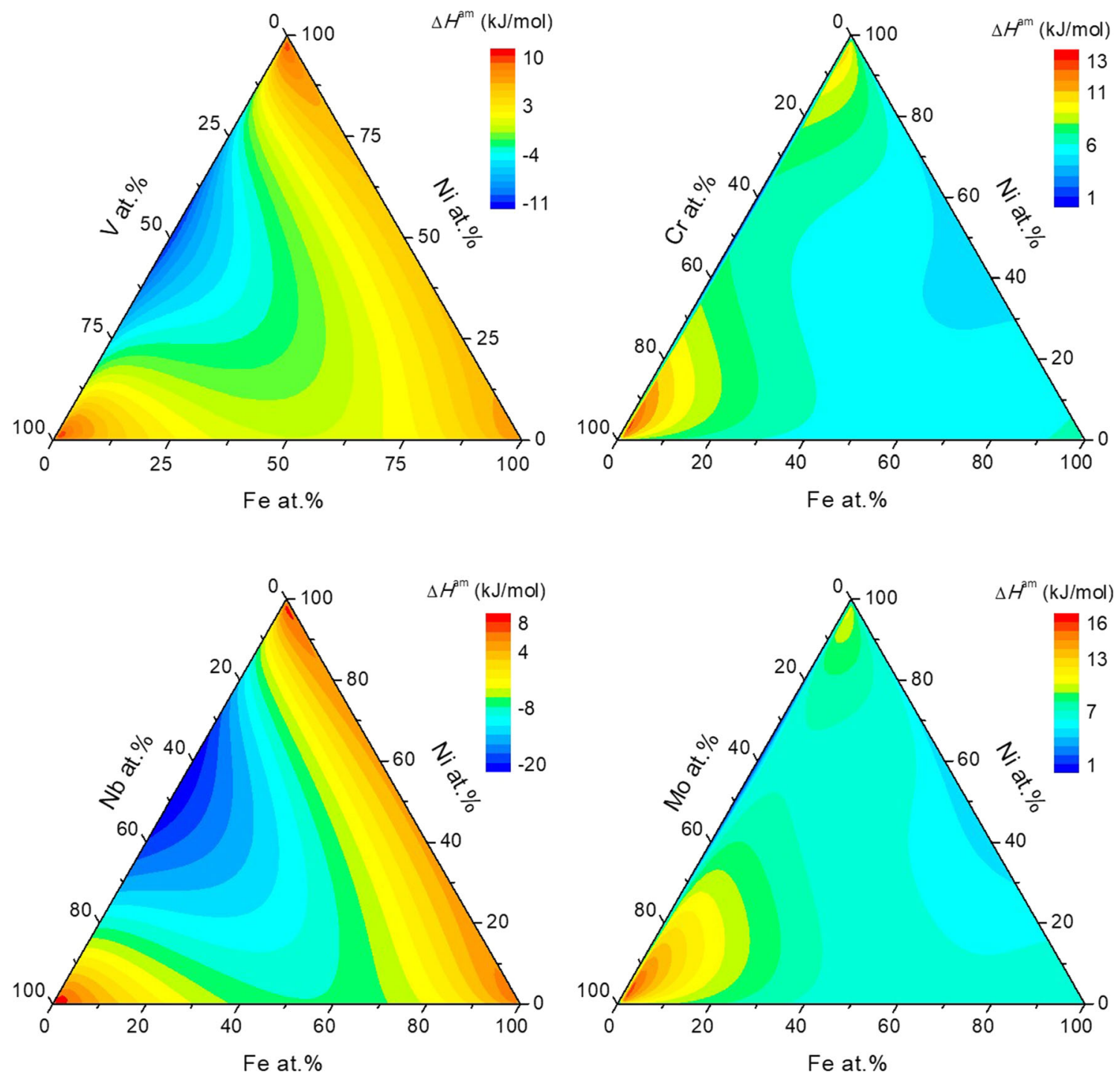

Fig. 1 - Compositional dependences of formation enthalpies of amorphous phase $\Delta H^{\mathrm{am}}$ of Fe-Ni-TM systems $(\mathrm{TM}=\mathrm{V}, \mathrm{Cr}, \mathrm{Nb}, \mathrm{Mo})$.

of amorphous phase among all analysed compositions in each phase diagram. It should be also underlined that analysed systems are at most marginal glass formers. Contour maps of differential enthalpy $\Delta H^{\mathrm{am}-\mathrm{ss}}=$ $\Delta H^{\mathrm{am}}-\Delta H^{\mathrm{ss}}$ are also shown for all analysed systems in Appendix (Figure A2). Recalling the comparison of $\Delta H^{\mathrm{am}}$ phase diagrams in Figure 1 and finding the formation enthalpy of solid solution for V-containing alloys as highly negative, $\mathrm{Nb}$ seems to be the element of choice when designing alloys with the highest GFA in described Fe-Ni-TM systems. This conclusion is supported by the data presented in Figure A2, where $\mathrm{Fe}-\mathrm{Ni}-\mathrm{Nb}$ alloys possess the most negative values of $\Delta H^{\mathrm{am}-\mathrm{ss}}$, indicating preferential formation of glassy state.

For group V elements, vanadium and niobium, there is clear trend visible in compositional dependence of enthalpy of formation of amorphous phase (Figure 1).
$\Delta H^{\mathrm{am}}$ becomes more negative for rather constant amount of TM atom and increasing content of $\mathrm{Ni}$ at the expense of $\mathrm{Fe}$. The most negative values of -11.13 and $-22.19 \mathrm{~kJ} / \mathrm{mol}$ were reached for $\mathrm{Ni}_{52} \mathrm{~V}_{48}$ and $\mathrm{Ni}_{54} \mathrm{Nb}_{46}$, respectively. For group VI elements, $\Delta H^{\mathrm{am}}$ has rather small range of variation and is positive for all compositions reaching maxima in the vicinity of $\mathrm{Cr}$-rich and Mo-rich corners. Smallest values indicating highest driving force for amorphization among all compositions containing $\mathrm{Cr}$ and $\mathrm{Mo}$ were found in the regions near to equiatomic Ni-Cr, Ni-Mo and Ni-Fe.

The dependence of normalized mismatch entropy on the composition of alloys is exhibited for Fe-Ni-TM $(\mathrm{TM}=\mathrm{V}, \mathrm{Cr}, \mathrm{Nb}, \mathrm{Mo}$ ) alloys in Figure 2. Normalized mismatch entropy reflects the effect of atomic radii mismatch between the main constituents. The $S_{\sigma} / k_{\mathrm{B}}=$ 0.1 was reported to be the critical value for the achievement of considerable GFA. ${ }^{[2]}$ The alloys which 

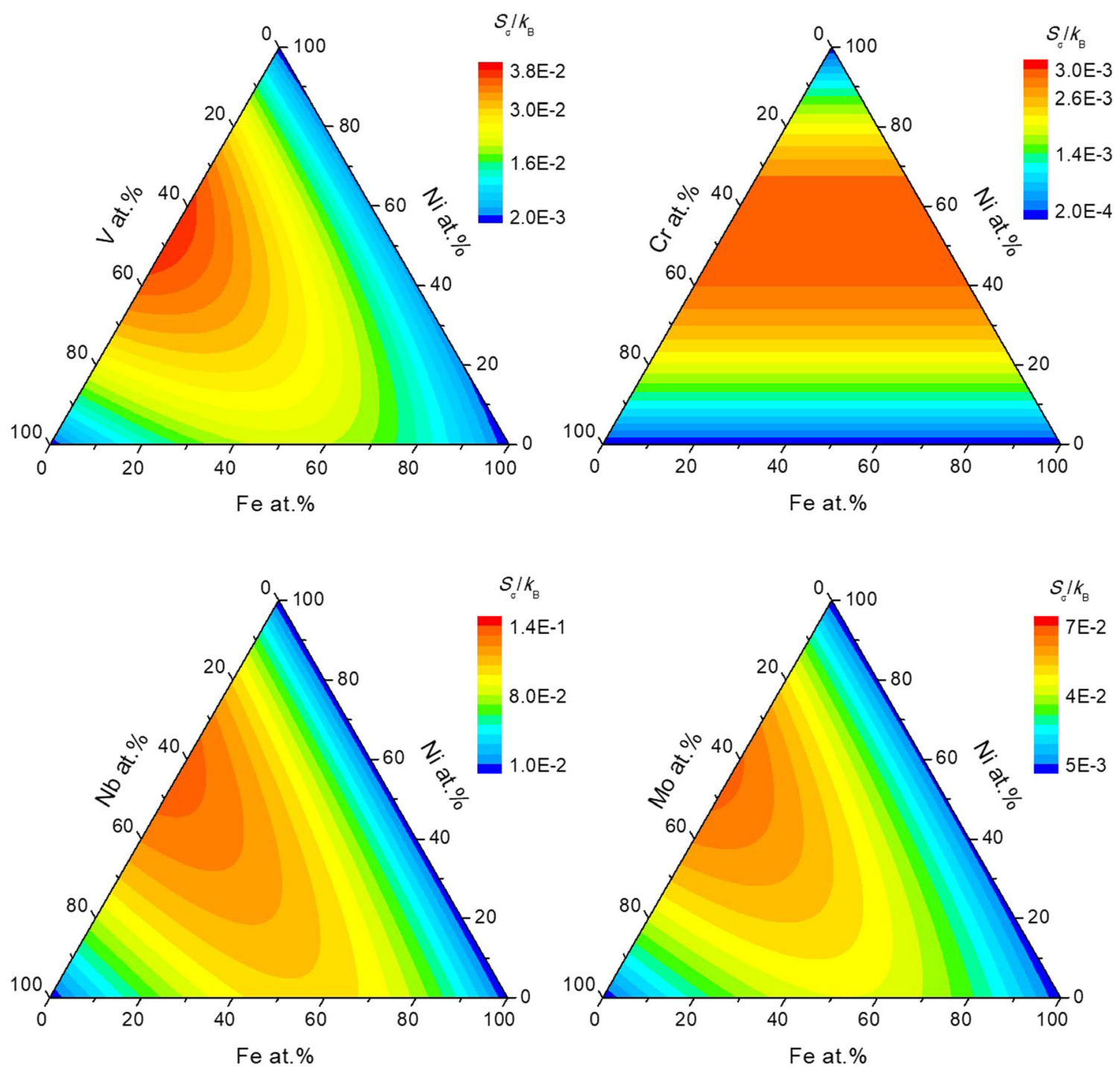

Fig. 2 - Compositional dependences of normalized mismatch entropy $S_{\sigma} / k_{\mathrm{B}}$ calculated for Fe-Ni-TM systems $(\mathrm{TM}=\mathrm{V}, \mathrm{Cr}, \mathrm{Nb}, \mathrm{Mo})$.

are characterized by higher values are reported to form amorphous structure more easily. This value, as expected, is reached only for some compositions from $\mathrm{Fe}-\mathrm{Ni}-\mathrm{Nb}$ phase diagram. It should be noted that variation range of $S_{\sigma} / k_{\mathrm{B}}$ is very low for each phase diagram, but mismatch entropy changes of more than one order of magnitude for different TM substitutions. Low values of $S_{\sigma} / k_{\mathrm{B}}$ are connected with similar atomic radii of all constituents with $r_{\mathrm{Fe}}=0.128 \mathrm{~nm}$, $r_{\mathrm{Ni}}=0.125 \mathrm{~nm}, \quad r_{\mathrm{V}}=0.136 \mathrm{~nm}, \quad r_{\mathrm{Cr}}=0.128 \mathrm{~nm}$, $r_{\mathrm{Nb}}=0.147 \mathrm{~nm}$ and $r_{\mathrm{Mo}}=0.14 \mathrm{~nm} \cdot{ }^{[23]}$ Due to the same $r$ value for $\mathrm{Fe}$ and $\mathrm{Cr}, S_{\sigma} / \mathrm{k}_{\mathrm{B}}$ changes with varying $\mathrm{Ni}$ content only. The conclusions drawn on the basis of the mismatch entropy calculations are in good agreement with the results of predictions of formation enthalpy of amorphous phase and indicate very weak driving force for vitrification for most compositions.

Compositional dependence of glass forming ability parameter $\Delta P_{\mathrm{HS}}$ is presented for Fe-Ni-TM $(\mathrm{TM}=\mathrm{V}$, $\mathrm{Cr}, \mathrm{Nb}, \mathrm{Mo}$ ) alloys in Figure 3. All $\Delta P_{\mathrm{HS}}$ contour maps resembles those of $\Delta H^{\mathrm{am}}$ and $S_{\sigma} / k_{\mathrm{B}}$ calculated for $\mathrm{V}$ and $\mathrm{Nb}$-containing alloys. $\Delta P_{\mathrm{HS}}$ reaches minimum for Fe-less compositions. Glass forming ability parameter is most negative in particular phase diagrams for $\mathrm{Ni}_{52} \mathrm{~V}_{48}$ $\left(\Delta P_{\mathrm{HS}}=-0.71 \mathrm{~kJ} / \mathrm{mol}\right), \mathrm{Ni}_{50} \mathrm{Cr}_{50}\left(\Delta P_{\mathrm{HS}}=-0.02\right.$ $\mathrm{kJ} / \mathrm{mol}), \mathrm{Ni}_{55} \mathrm{Nb}_{45}\left(\Delta P_{\mathrm{HS}}=-4.34 \mathrm{~kJ} / \mathrm{mol}\right)$, and $\mathrm{Ni}_{53} \mathrm{Mo}_{47}\left(\Delta P_{\mathrm{HS}}=-0.52 \mathrm{~kJ} / \mathrm{mol}\right)$. The results of thermodynamic calculations are unambiguous, indicating $\mathrm{Fe}-\mathrm{Ni}-\mathrm{Nb}$ as the best glass-forming alloys among all analyzed systems. 

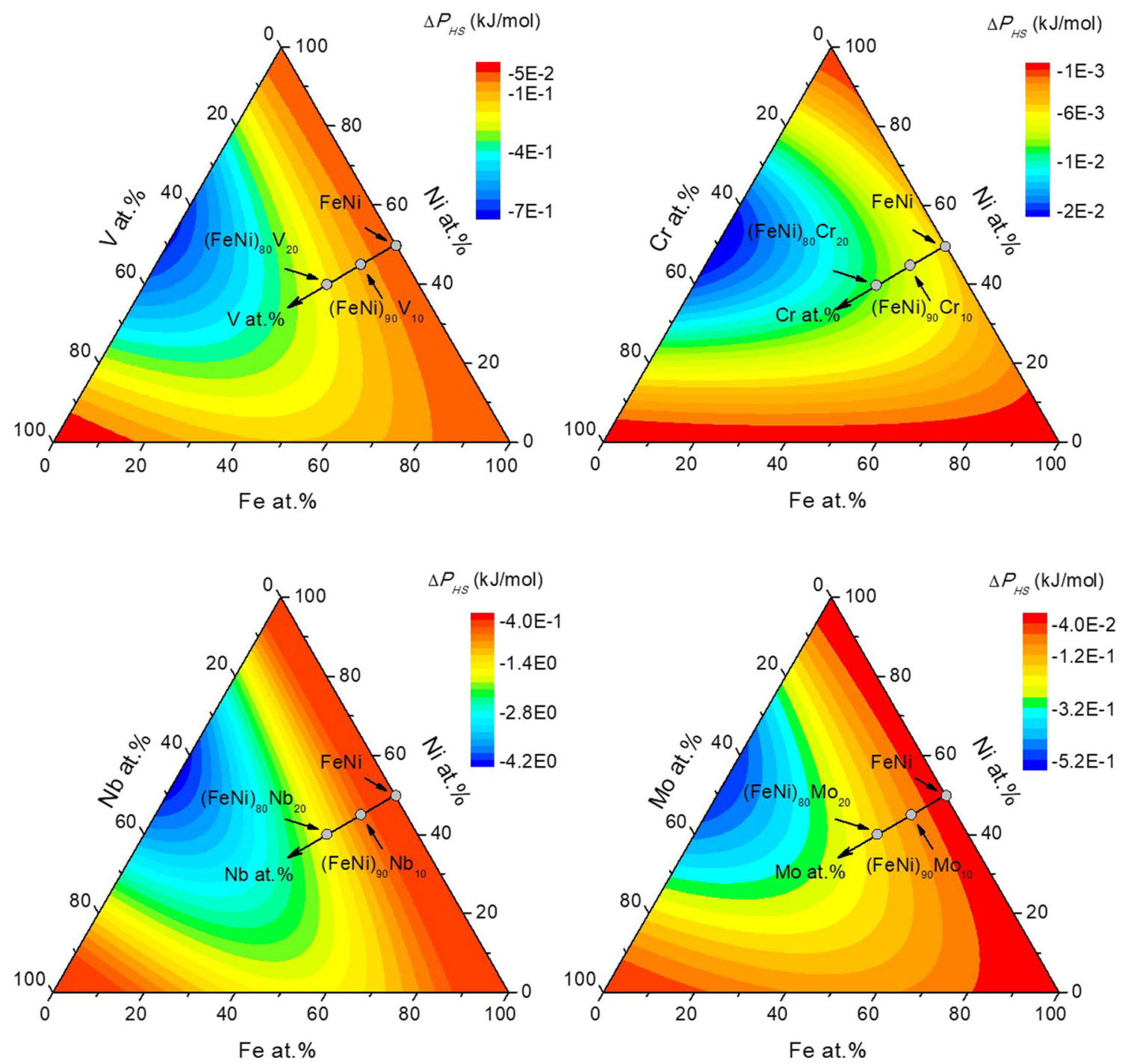

Fig. 3 - Compositional dependences of glass-forming ability parameter $\Delta P_{\mathrm{HS}}$ calculated for Fe-Ni-TM systems $(\mathrm{TM}=\mathrm{V}, \mathrm{Cr}, \mathrm{Nb}, \mathrm{Mo})$. Grey dots represent $(\mathrm{FeNi})_{100-x} \mathrm{TM}_{x}(x=0,10,20)$ alloys with equal amount of $\mathrm{Fe}$ and $\mathrm{Ni}$ and increasing content of $\mathrm{TM}$ (along black arrow).

As stated in the introduction, the general aim is not only connected with maximization of GFA but also with optimization of soft magnetic properties of FeNi-based alloys. Therefore, grey dots representing $(\mathrm{FeNi})_{100-x} \mathrm{TM}_{x}(x=0,10,20)$ alloys with high (and equiatomic for simplicity) content of $\mathrm{Fe}$ and $\mathrm{Ni}$ were added to Figure 3 as a guide. Moreover, the same dependence for $(\mathrm{FeNi})_{100-x} \mathrm{TM}_{x}$ was depicted in the form of pseudo-binary diagrams for a whole range of $x$ in Figure 4, along with enthalpies of formation of amorphous phase. Visualization of the influence of TM substitution on the GFA in the easy to perceive way was the main purpose for the selection of chosen stoichiometries. Nevertheless, compositional dependences of $\Delta H^{\mathrm{am}}$ and $\Delta P_{\mathrm{HS}}$ are similar for the wide range of $\mathrm{Fe} / \mathrm{Ni}$ ratios.

Both $\Delta H^{\mathrm{am}}$ and $\Delta P_{\mathrm{HS}}$ dependences presented in Figure 4 exhibit minima in most cases, except formation enthalpies of amorphous phase for $\mathrm{FeNi}-\mathrm{Cr}$ and
FeNi-Mo pseudobinary systems. In general, one can see that the substitution of small amounts of $\mathrm{Fe}$ and $\mathrm{Ni}$ by group $\mathrm{V}$ transition metals, especially $\mathrm{Nb}$, changes sign of enthalpy of formation of amorphous phase to negative, suggesting improved GFA. For other metals this changes are insignificant and of rather small importance for further experiments. Similar behavior is observed for glass forming ability parameter, where $\mathrm{Nb}$-containing alloys reach the most negative values among all analyzed systems.

As it is intended to utilize obtained results for further experimental works and to design low-dimensional single-phase amorphous or nanoglass samples with maximized FeNi content, described results can be useful in designing alloys' compositions. Group V elements are preferred substitutional elements in this case, with $\mathrm{Nb}$ as the most promising candidate among all analyzed transition metals. 

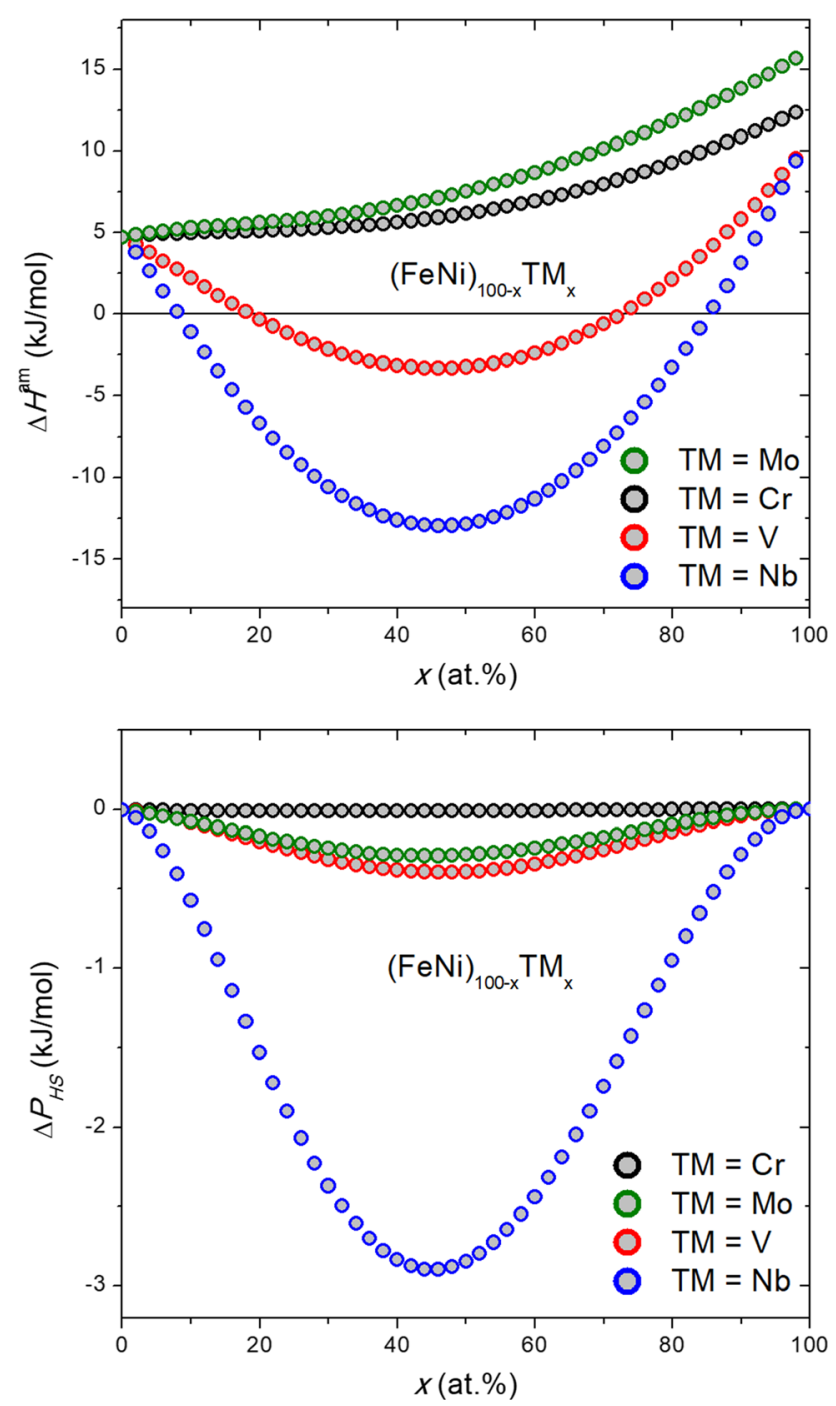

Fig. 4 -Compositional dependences of formation enthalpies of amorphous phase $\Delta H^{\mathrm{am}}$ (upper) and glass forming ability parameter $\Delta P_{\mathrm{HS}}$ (bottom) calculated for $(\mathrm{FeNi})_{100-x} \mathrm{TM}_{x}$ alloys $(0 \leq x \leq 100$, $\mathrm{TM}=\mathrm{V}, \mathrm{Cr}, \mathrm{Nb}, \mathrm{Mo})$.

One should bear in mind that kinetic parameters were not taken into account in the calculations and in specific conditions (for high cooling rates) formation of amorphous phases is highly probable in analyzed systems. Better GFA can be advantageous in tuning of packing density of amorphous alloys or sizes and density of distinguishable regions in nanoglasses.

The results of thermodynamic calculations resemble experimental and simulation results obtained for multinary transition metal systems. Among all compositions described in the paper, bulk metallic glasses, which are characterized by high GFA, have been synthesized mostly for $\mathrm{Ni}-\mathrm{Nb}$-based systems. It has been shown, utilizing molecular dynamics simulations with embedded atom method, that increase in $\mathrm{Nb}$ content, up to 38 at. pct, causes improvement of GFA of $\mathrm{Ni}-\mathrm{Nb}$ binary system. ${ }^{[24]}$ This value is consistent with the most negative value of $\Delta P_{H S}$ for $\mathrm{Ni}-\mathrm{Nb}$ binaries, determined here for $\mathrm{Ni}_{55} \mathrm{Nb}_{45}$ and matches qualitatively with the results presented for ternary $\mathrm{Ni}-\mathrm{Nb}$-Ti system. ${ }^{[25]} \mathrm{Nev}-$ ertheless, bulk metallic glasses of $\mathrm{Ni}-\mathrm{Nb}$ have been synthesized sporadically, e.g., by quenching of highly undercooled melts. ${ }^{[2]}$ Except Ni-Nb, also alloys with group IV transition metal, so $\mathrm{Ni}-\mathrm{Zr}$ and $\mathrm{Ni}-\mathrm{Nb}-\mathrm{Zr}$, are known as the best glass formers among Ni-TM systems. ${ }^{[27]} \mathrm{Ni}_{60} \mathrm{Nb}_{40}$ and $\mathrm{Ni}_{60} \mathrm{Zr}_{40}$ have been also successfully synthesized by mechanical alloying. ${ }^{[28]}$ Moreover, it has been shown that $\mathrm{V}$, Mo and especially $\mathrm{Cr}$ has less significant or even deteriorative impact on the formation of glassy state in transition metal-based systems. ${ }^{[17,29,30]}$

\section{CONCLUSIONS}

Concluding, the highest GFA among all analyzed compositions, so higher driving force for vitrification, was determined for Fe-Ni-TM alloys with TM belonging to group $\mathrm{V}$ in the periodic table, especially $\mathrm{Nb}$ (in contrast to group VI elements). The advantage of $\mathrm{Nb}$ and $\mathrm{V}$ results from significant differences of potential $(\varphi)$ and density of electrons at the boundary of WignerSeitz cell $\left(n_{\mathrm{ws}}\right)$ comparing to $\mathrm{Fe}$ and $\mathrm{Ni}$. This leads to more negative values of interfacial enthalpy for $\mathrm{Fe}-\mathrm{Nb}$, $\mathrm{Ni}-\mathrm{Nb}, \mathrm{Fe}-\mathrm{V}$ and $\mathrm{Ni}-\mathrm{V}$ atomic pairs and preferential formation of amorphous phase. The most negative values of glass forming ability parameter, indicating the highest GFA, were reached for compositions close to equiatomic $\mathrm{Ni}-\mathrm{Nb}$ alloy. Presented results show that relatively simple thermodynamic criteria can be used to determine glass forming ability of ternary transition metal systems and can shed some light on the routes to design new functional materials with unique structure and/or morphology, which could be beneficial in optimization of various properties.

\section{OPEN ACCESS}

This article is licensed under a Creative Commons Attribution 4.0 International License, which permits use, sharing, adaptation, distribution and reproduction in any medium or format, as long as you give appropriate credit to the original author(s) and the source, provide a link to the Creative Commons licence, and indicate if changes were made. The images or other third party material in this article are included in the article's Creative Commons licence, unless indicated otherwise in a credit line to the material. If material is not included in the article's Creative Commons licence and your intended use is not permitted by statutory regulation or exceeds the permitted use, you will need to obtain permission directly from the copyright holder. To view a copy of this licence, visit http://creat ivecommons.org/licenses/by/4.0/.

\section{APPENDIX}

See Figures A1 and A2. 

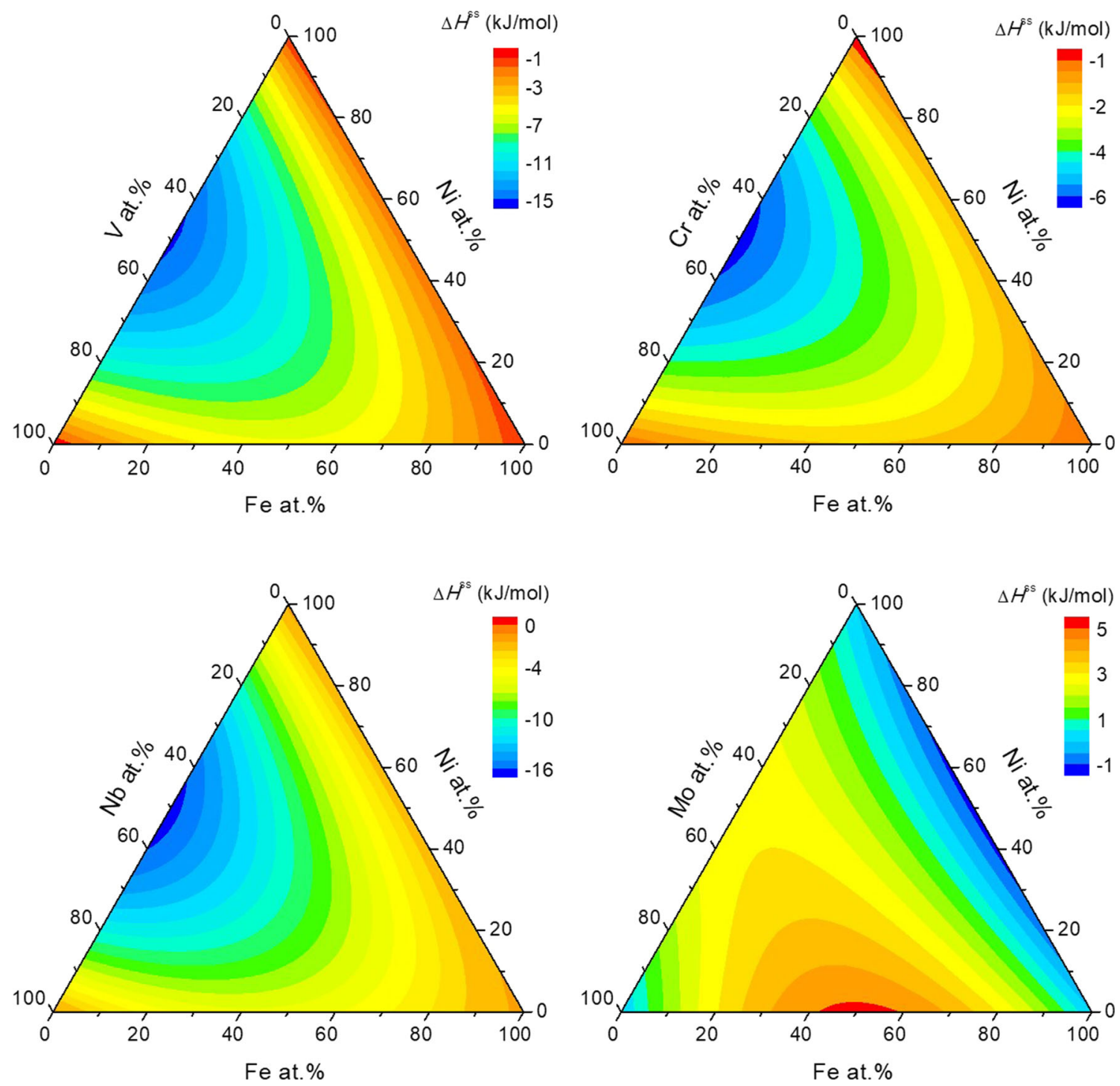

Fig. A1-Compositional dependences of formation enthalpies of solid solution $\Delta H^{\mathrm{ss}}$ of Fe-Ni-TM systems $(\mathrm{TM}=\mathrm{V}, \mathrm{Cr}, \mathrm{Nb}, \mathrm{Mo})$. 

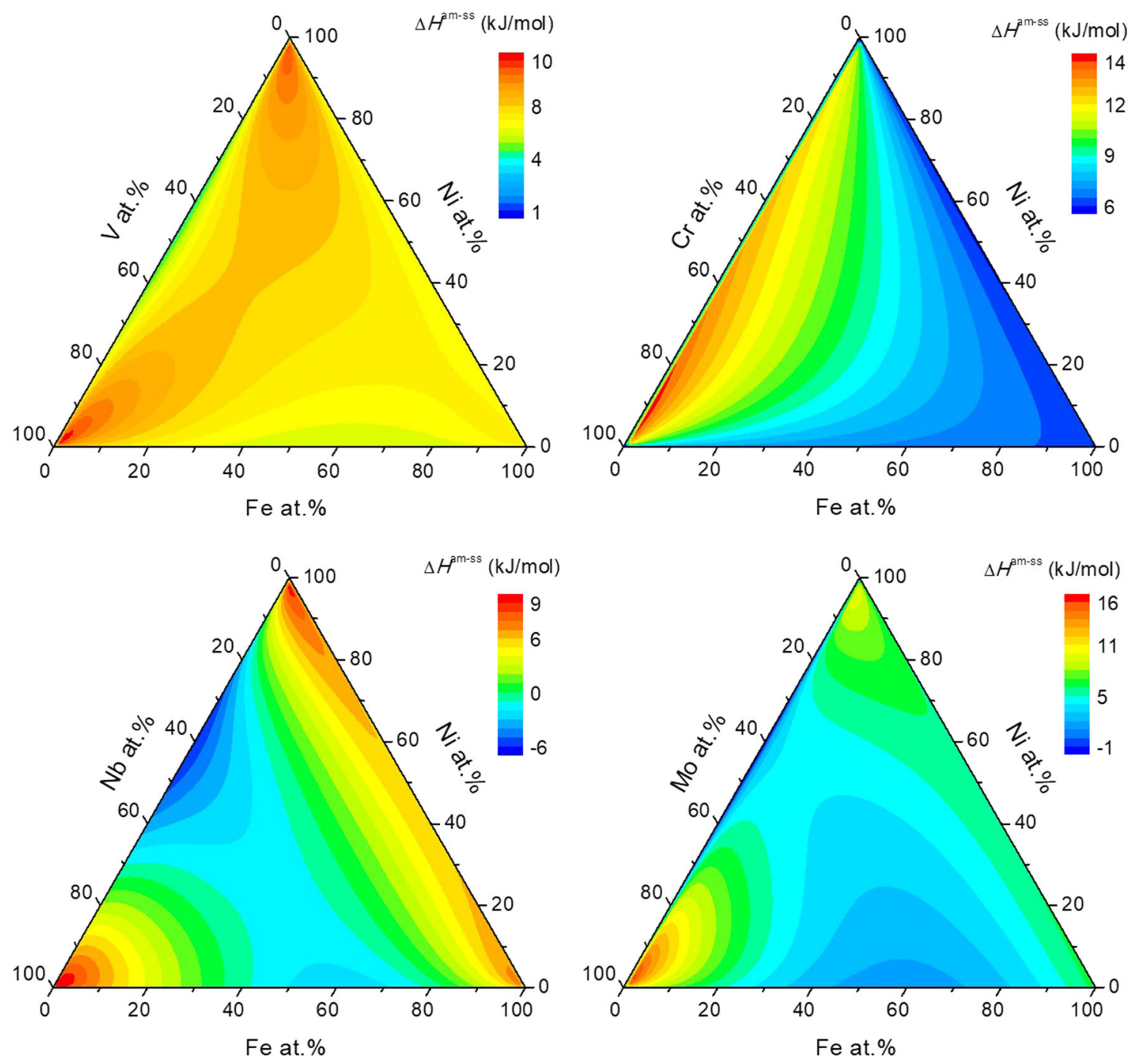

Fig. A2 - Compositional dependences of difference of formation enthalpies of amorphous phase and solid solution $\Delta H^{\mathrm{am}-\mathrm{ss}}$ of Fe-Ni-TM systems $(\mathrm{TM}=\mathrm{V}, \mathrm{Cr}, \mathrm{Nb}, \mathrm{Mo})$.

\section{REFERENCES}

1. E. Kaniusas, H. Pfützner, L. Mehnen, J. Kosel, J.C. Téllez-Blanco, G. Varoneckas, A. Alonderis, T. Meydan, M. Vázquez, M. Rohn, A.M. Merlo, and B. Marquardt: IEEE Sens. J., 2006, vol. 6, pp. 819-28.

2. M.K. Park and B.A. Chin: J. Microbiol. Biotechnol., 2016, vol. 26, pp. 2051-59.

3. L. Ren and K. Yu: Materials, 2019, vol. 12, pp. 1135-59, https:// doi.org/10.3390/ma12071135.

4. C. Liang, C.P. Gooneratne, Q.X. Wang, Y. Liu, Y. Gianchandani, and J. Kosel: Biosensors, 2014, vol. 4, pp. 189-203.

5. M.L. Johnson, J. Wan, S. Huang, Z. Cheng, V.A. Petrenko, D.J. Kim, I.H. Chen, J.M. Barbaree, J.W. Hong, and B.A. Chin: Sens. Actuators A Phys., 2008, vol. 144, pp. 38-47.

6. C. Liang, C. Gooneratne, D. Cha, L. Chen, Y. Gianchandani, and J. Kosel: J. Appl. Phys., 2012, vol. 112, art. no. 113912, https:// doi.org/10.1063/1.4768458.

7. Z. Śniadecki, D. Wang, Y. Ivanisenko, V.S.K. Chakravadhanula, C. Kübel, H. Hahn, and H. Gleiter: Mater. Charact., 2016, vol. 113 , pp. $26-33$.

8. H. Gleiter: Beilstein J. Nanotechnol., 2013, vol. 4, pp. 517-33.

9. A. Takeuchi and A. Inoue: Mater. Trans., 2005, vol. 46, pp. 2817-29.

10. A. Inoue: Acta Mater., 2000, vol. 48, pp. 279-306.
11. Z.P. Lu and C.T. Liu: Acta Mater., 2002, vol. 50, pp. 3501-12.

12. D. Miracle and O. Senkov: Mater. Sci. Eng. A, 2003, vol. 347, pp. $50-58$

13. J. Bhatt, W. Jiang, X. Junhai, W. Qing, C. Dong, and B.S. Murty: Intermetallics, 2007, vol. 15, pp. 716-21.

14. F.R. De Boer, R. Boom, W.C.M. Mattens, A.R. Miedema, and A.K. Niessen: Cohesion in Metals, vol. 1, F.R. De Boer, D.G. Pettifor, eds., North Holland, Amsterdam, 1988.

15. H. Bakker: Enthalpies in Alloys: Miedema's Semi-Empirical Model, Materials Science Foundations 1, Trans Tech Publications Ltd., Zurich, 1998.

16. Z. Śniadecki, J.W. Narojczyk, and B. Idzikowski: Intermetallics, 2012, vol. 26, pp. 72-77.

17. Z. Śniadecki, A. Musiał, and A.R. Kilmametov: Mater. Charact., 2017, vol. 132, pp. 46-52.

18. G.A. Mansoori, N.F. Carnahan, K.E. Starling, and T.W. Leland: J. Chem. Phys., 1971, vol. 54, pp. 1523-25.

19. Y. Ouyang, X. Zhong, Y. Du, Z. Jin, Y. He, and Z. Yuan: $J$. Alloys Compd., 2006, vol. 416, pp. 148-54.

20. Y. Ouyang, X. Zhong, Y. Du, Y. Feng, and Y. He: J. Alloys Compd., 2006, vol. 420, pp. 175-81.

21. K.-C. Chou: Calphad, 1995, vol. 19, pp. 315-25.

22. A. Takeuchi and A. Inoue: Trans. Jpn. Inst. Met., 2000, vol. 41, pp. $1372-78$ 
23. Smithells Metals Reference Book, 7th ed., E.A. Brandes, and G. Brook, eds., Smithells Metals Reference Book, 7th ed., Butterworth-Heinemann Ltd., Oxford, 1992.

24. K. Vijay Reddy and S. Pal: J. Non. Cryst. Solids, 2017, vol. 471, pp. 243-50.

25. Y. Li, J.H. Li, J.B. Liu, and B.X. Liu: RSC Adv., 2015, vol. 5, pp. 3054-62.

26. M. Leonhardt, W. Löser, and H.G. Lindenkreuz: Acta Mater., 1999, vol. 47, pp. 2961-68.

27. Z.W. Zhu, H.F. Zhang, W.S. Sun, and Z.Q. Hu: J. Mater. Res., 2007, vol. 22, pp. 453-59.
28. M.H. Enayati and E. Dastanpoor: Metall. Mater. Trans. A, 2013, vol. 44A, pp. 3984-98.

29. Y. Waseda, H.-S. Chen, K. Thomas Jacob, and H. Shibata: Sci. Technol. Adv. Mater., 2008, vol. 9, art. no. 023003.

30. A. Hitit, Ş. Talaş, and R. Kara: Indian J. Eng. Mater. Sci., 2014, vol. 21 , pp. 111-15.

Publisher's Note Springer Nature remains neutral with regard to jurisdictional claims in published maps and institutional affiliations. 